\title{
Observations on a magnetotactic bacteria-grazing ciliate in sediment from the intertidal zone of Huiquan Bay, China*
}

\author{
CHEN Si ${ }^{1,2,3,4}$, CUI Kaixuan ${ }^{1,2,3,4}$, ZHANG Wenyan ${ }^{1,3,4,5}$, ZHAO Yicong ${ }^{1,2,3,4}$, XIAO Tian ${ }^{1,3,4,5}$, \\ PAN Hongmiao ${ }^{1,3,4,5^{* *}}$, ZHANG Wuchang ${ }^{1,3,4, * *}$, WU Long-Fei ${ }^{5,6}$
}

CHEN et al.: Occurrence of a magnetotactic bacteria-grazing ciliate

${ }^{1}$ CAS Key Laboratory of Marine Ecology and Environmental Sciences, Institute of Oceanology, Chinese Academy of Sciences, Qingdao 266071, China

${ }^{2}$ University of Chinese Academy of Sciences, Beijing 100049, China

${ }^{3}$ Laboratory for Marine Ecology and Environmental Science, Qingdao National Laboratory for Marine Science and Technology, Qingdao 266237, China

${ }^{4}$ Center for Ocean Mega-Science, Chinese Academy of Sciences, Qingdao 266071, China

${ }^{5}$ International Associated Laboratory of Evolution and Development of Magnetotactic Multicellular Organisms (LIA-MagMC),

CNRS-CAS, Marseille-Beijing-Qingdao-Sanya.

${ }^{6}$ Aix Marseille Univ, CNRS, LCB, IM2B, IMM, Marseille, 13009, France

* Supported by the National Natural Science Foundation of China (Nos. 41776130 \& 41776131) and the National Natural Science Foundation of

China-Shandong Joint Fund for Marine Science Research Centers (U1706208).

** Corresponding author: PAN Hongmiao E-mail: panhongmiao@qdio.ac.cn; Tel.: 86-532-82898593; Fax: 86-532-82898586.

ZHANG Wuchang E-mail: wuchangzhang@qdio.ac.cn; Tel.: 86-532-82898937; Fax: 86-532-82898586.

Corresponding address: CAS Key Laboratory of Marine Ecology \& Environmental Sciences, Institute of Oceanology Chinese Academy of Sciences, 7 Nanhai Rd., Qingdao 266071, CHINA.

Abstract Magnetotactic bacteria (MTB) are a group of prokaryotes having the ability to orient and swim along geomagnetic field lines because they contain intracellular magnetosomes, which are synthesized through a biomineralization process. Magnetosomes have recently also been found in unicellular eukaryotes, which are referred to as magnetically responsive protists (MRPs). The magnetosomes have three origins in MRPs. In this study we characterized a MTB-grazing ciliated MRP that was magnetically collected from intertidal sediment of Huiquan Bay, China. Based on 18S rRNA gene sequence analysis, the ciliated MRP was tentatively identified as Uronemella parafilificum HQ. Using transmission electron microscopy, we observed that magnetosomes having 
2-3 shapes were randomly distributed within this ciliate. Energy-dispersive X-ray spectroscopy and high-resolution transmission electron microscopy images of the magnetosomes were consistent with them being composed of magnetite. Magnetosomes having the same shape and mineral composition were also detected in MTB that occurred in the same environment as the ciliated MRP. Statistical analysis showed that the size and shape of the magnetosomes in the ciliated MRP were similar to those in MTB. The results suggest that this ciliated MRP can graze, ingest, and digest various types of MTB. It is certainly worth noting that this is the first record of MRPs in Asian aquatic sediment and suggesting they might be widely distributed. These results also support the assertion that MRPs probably contribute to the ecological cycles of iron, and expand possibilities for research into the mechanism of magnetoreception in eukaryotes.

Keywords: magnetically responsive protist, ciliate, magnetotactic bacteria, magnetosome, graze, magnetoreception

\section{INTRODUCTION}

Magnetotactic bacteria (MTB) are widely distributed in freshwater and marine sediments (Blakemore, 1975; Frankel et al., 1979). Their morphologies include cocci, ovoid, rod, curved rod, spirillum, and multicellular forms (the multicellular magnetotactic prokaryotes: MMPs) (Amor et al., 2020; Rodgers et al., 1990). Among prokaryotic microorganisms, the MTB have for decades been known to have the ability to sense magnetic fields. Their magnetotactic behavior is based on intracellular magnetosomes that are formed by intracellular biomineralization, and these enable cell orientation relative to magnetic fields. Magnetosomes are composed of magnetite $\left(\mathrm{Fe}_{3} \mathrm{O}_{4}\right)$ or/and greigite $\left(\mathrm{Fe}_{3} \mathrm{~S}_{4}\right)$ (Zhang et al., 2014), and occur in cells in diverse shapes and arrangements. The shapes include elongated prisms, cuboctahedrons, bullet-shaped, and tooth-shaped forms; they are predominantly arranged in single, double, or multiple chains, although disorderly arrangements have also been reported (Amor et al., 2020). The composition, morphology, arrangement, and sizes of magnetosomes are species specific among MTB, and are strongly correlated with MTB phylogeny (Lefèvre et al., 2013).

The first microeukaryote (a dinoflagellate) showing obvious magnetotactic behavior was found in 1986 (Torres de Araujo et al., 1986). Subsequently, a number of unicellular eukaryotes (including flagellates and ciliates) that can sense and respond to magnetic fields have been reported (Bazylinski et al., 2000); these are termed magnetically responsive protists (MRPs), and 
their occurrence provides more evidence for magnetoreception among eukaryotes (Leão et al., 2020; Martins et al., 2007; Monteil et al., 2018, 2019). Studies have shown that there are three sources of magnetosomes in MRPs: (1) intracellular biomineralization by the protists (Leão et al., 2020; Torres de Araujo et al., 1986); (2) ectosymbiotic MTB (Monteil et al., 2019); and (3) MTB preyed upon by the protists (Martins et al., 2007; Monteil et al., 2018).

The first MRP, isolated from sediments of a coastal mangrove swamp, was identified by morphological examination as Anisonema platysomum (Euglenophyceae) (Torres de Araujo et al., 1986), and was found to contain thousands of bullet-shaped magnetosomes within its cell. However, the magnetosomes in MTB from the same environmental sample predominantly contained cuboctahedron and elongated pseudohexagonal prism-shaped magnetosomes. Therefore, it was concluded that the magnetosomes in A. platysomum are formed by internal biomineralization (Torres de Araujo et al., 1986). Four types of MRP were reported from the water column of a chemically stratified coastal salt pond (Bazylinski et al., 2000). Two of these, a dinoflagellate and a cryptomonad, were presumed to biomineralize magnetosomes internally, based on the magnetotactic behavior and the morphology of the magnetosome-like particles. The other two MRPs will be discussed later in this section. A flagellated protist having bullet-shaped intracellular magnetosomes was recently reported from freshwater river sediment (Leão et al. 2020). Although bullet-shaped magnetosomes were also observed in MTB in the same environment, there were significant differences in the shape, size, and crystal properties of the MRP and MTB magnetosomes. Hence, it was suggested that the flagellated MRP can synthesize magnetosomes autonomously (Leão et al., 2020). However, detailed molecular analysis was unavailable for this MRP. A fascinating form of magnetoreception in eukaryotes is facilitated by magnetic ectosymbiotic bacteria (MEB), which live on the surface of an excavate protist (Euglenozoa) (Monteil et al., 2019). This symbiotic relationship enables access to more favorable habitats and efficient use of nutrients (Monteil et al., 2019). The above findings have provided insights into the origin and evolution of magnetoreception in eukaryotes.

In addition to the above two sources of magnetosomes, MRPs can also acquire magnetosomes by preying on MTB and accumulating their magnetosomes. Brazilian scholars isolated a ciliate (Euplotes vannus) from lagoon sediment and conducted experiments in which the ciliate was fed MMPs under laboratory conditions. This showed that the ciliates can graze MMPs 
and form acidic food vacuoles to digest the MMPs and magnetosomes. However, the ciliates did not respond to changes in the magnetic field, although this may have been because too few magnetosomes were accumulated within the ciliate cells (Martins et al., 2007). In natural environments, such as the chemically stratified coastal salt pond noted above, one of the four types of MRPs (another cryptomonad) was considered to be capable of consuming MTB, based on observations of the presence of vacuole-like inclusions (Bazylinski et al., 2000). Furthermore, a ciliate identified by morphological and molecular characteristics as Uronema marinum was able to graze large numbers of MTB and dissolve the magnetosomes in its vacuoles (Monteil et al., 2018). All data suggested that MTB-grazing protists play an important role in the biogeochemical cycling of iron by dissolving the magnetosomes and returning iron to the environment. To date, few types of MTB-grazing protists have been found, and research remains limited to characterizing them and expanding knowledge of their diversity. Clearly, more research is needed to clarify the magnetic response mechanism in these eukaryotes. In this study we used morphological comparison and 18S rRNA sequence analysis to characterize a population of benthic ciliates that graze magnetotactic bacteria in a natural environment.

\section{MATERIAL AND METHOD}

\subsection{Sampling site description, sample collection, microcosm setup, and magnetic enrichment}

Sediment samples were collected from the intertidal zone of Huiquan Bay, Qingdao, China $\left(36^{\circ} 03^{\prime} 36.69^{\prime \prime} \mathrm{N}, 120^{\circ} 21^{\prime} 5.09^{\prime \prime} \mathrm{E}\right)$ in July 2019 . For sample collection we removed the surface gravel and yellow sediments, and collected the subsurface gray-black sediments and in-situ seawater in $500 \mathrm{ml}$ plastic sampling bottles. Prior to magnetic enrichment of MTB and MRPs, the bottles containing sediment and water were incubated as microcosms for two weeks with the lids half open in the dark (to prevent photosynthesis) at room temperature $\left(\sim 25^{\circ} \mathrm{C}\right)$, and without agitation.

For magnetic enrichment, two permanent button magnets ( $16 \mathrm{mT}$ each) were fixed relatively parallel to and slightly above the sediment-water interface, one on each side of the microcosm, with the south pole towards the bottle. The water and sediment were then mixed evenly, and the bottles were again placed in the dark to enable settling of the sediment (Pan et al., 2008). After approximately $30 \mathrm{~min}$, gray and black spots were evident on the inner wall of the bottle adjacent 
to the attached magnets. Pasteur pipettes were used to collect the material forming the gray-black spots. A sample of approximately $1 \mathrm{ml}$ containing sediment and water was removed and placed in a $2 \mathrm{ml}$ centrifuge tube. After the sediment settled at the bottom of the centrifuge tube, 5-10 $\mu \mathrm{l}$ of the sediment and water was removed to prepare a cover glass hanging drop for microscopy (Schüler, 2002). A parallel magnetic field was applied to the hanging drop by placing a permanent magnet $(40 \mathrm{mT})$ on each side of the drop, and the microbes in the drop were observed using differential interference contrast (DIC) microscopy (Olympus BX51 microscope equipped with a DP80 camera system; Olympus, Tokyo, Japan). Samples containing MRPs and MTB were screened for purification. The 2-ml centrifuge tubes with samples containing protists and MTB were connected to a l-ml pipette tip and a PCR tube in sequence. The entire device was filled with filtered in-situ seawater and placed in a strong magnetic field created by two permanent magnets (54 mT each) placed in parallel (Fig.1). After approximately $2 \mathrm{~h}$ the purified MRPs or MTB were obtained for subsequent experimental analysis.

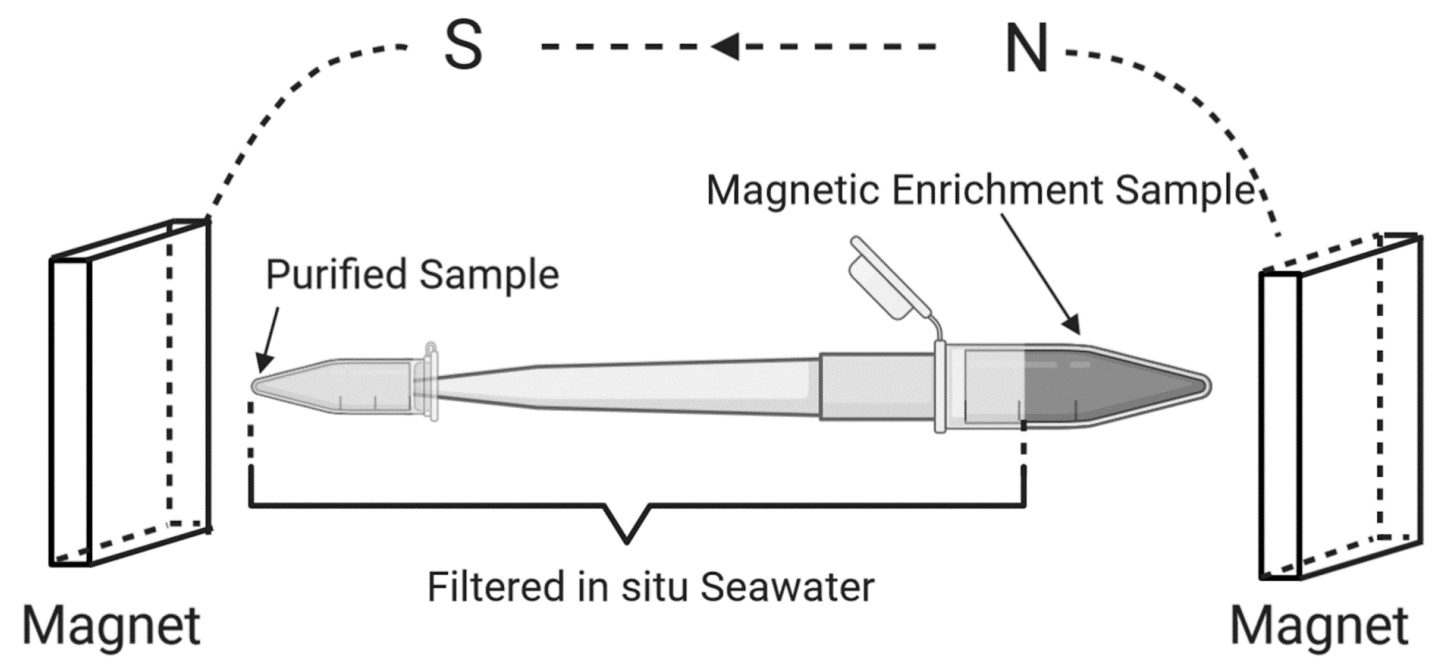

Fig.1 Schematic diagram of the purification method.

\subsection{Observations of MRP and MTB}

The DIC system was used to observe the morphology and movement of individual protists and MTB exposed to the magnetic field, and images and videos were used for analysis.

For transmission electron microscopy (TEM) observations a 5- $\mu$ l purified sample of MTB or protists was placed on a carbon-coated TEM grid. To increase cell adhesion, the grids were placed on the S pole of a magnet. As the drops of water were about to dry, the grids were washed 2-3 
times using Milli-Q water, then left to air dry at room temperature (Pan et al., 2019).

The morphological characteristics of the MTB and MRP were observed using a Hitachi H8100 microscope operating at $100 \mathrm{kV}$. High resolution transmission electron microscopy (HRTEM), selected area electron diffraction (SAED), and X-ray energy-dispersive spectroscopy (XEDS) were carried out using a JEOL JEM-2100 TEM operated at $200 \mathrm{kV}$ at the Institute of Geology and Geophysics, Chinese Academy of Sciences (IGGCAS).

\subsection{Data processing and statistical analysis}

The length and width of the MTB and MRP cells and magnetosomes were measured using Adobe Photoshop software. Gatan Digital Micrograph was used for the calculation of the diffraction pattern and measurement of the crystal lattice. Scatter plots of crystal length and width, the frequency distributions of magnetosome length, width, size (calculated as (length + width)/2), and shape factors (width/length) were conducted using Origin software.

\subsection{Phylogenetic Analysis}

Total DNA was extracted from purified samples using the DNeasy Blood \& Tissue Kit (QIAGEN, Germany), and PCR amplification (Mastercycler; Eppendorf, Germany) was undertaken using the universal eukaryote primers EukA (5'-AACCTGGTTGATCCTGCCAGT-3') and EukB (5'-TGATCCTTCTGCAGGTTCACCTAC-3') (Medlin et al., 1988) (Sangon Biotech, Shanghai, China). The PCR reaction conditions described by Wang et al. (2018) were modified as follows: $98^{\circ} \mathrm{C}$ for $30 \mathrm{~s}, 18$ cycles of $98^{\circ} \mathrm{C}$ for $10 \mathrm{~s}, 69-52^{\circ} \mathrm{C}$ touch down for $30 \mathrm{~s}$, and $72^{\circ} \mathrm{C}$ for 1 $\min$; then 18 cycles of $98^{\circ} \mathrm{C}$ for $10 \mathrm{~s}, 51^{\circ} \mathrm{C}$ for $30 \mathrm{~s}$, and $72^{\circ} \mathrm{C}$ for $1 \mathrm{~min}$; and a final extension at $72^{\circ} \mathrm{C}$ for $10 \mathrm{~min}$. The PCR product was purified using TaKaRa MiniBEST Agarose Gel DNA Extraction Kit Ver. 4.0 (TaKaRa, Dalian, China). The purified PCR products were cloned into the pMD18-T vector (TaKaRa, Dalian, China), and transformed into competent E. coli TOP10 cells. Randomly selected single clones were full-length sequenced by TsingKe Biological Technology (Qingdao, China).

The 18S rRNA gene sequences were analyzed using the BLAST search program on the NCBI website (http://www.ncbi.nlm.nih.gov/BLAST/). Relevant 18S rRNA gene sequences were selected from the NCBI GenBank database for the phylogenetic analyses, and sequences were 
aligned using the ClustalW algorithm. A phylogenetic tree was constructed using the maximum likelihood method in MEGA 6.0 (Tamura et al., 2013), with bootstrapping using 1000 replicates.

\section{RESULT}

\subsection{Occurrence of magnetically responsive microorganisms}

A large number of MTB and one protist type were observed in the droplets of magnetically purified samples observed using optical microscopy (Fig.2A1). The protist swam quickly and with rapid forward and reverse movements around the edge of the droplet, rotating around its longitudinal body axis (video S1). The cells were elongate obovate, had an average size of $22.47 \pm$ $1.94 \times 10.25 \pm 1.70 \mu \mathrm{m}$ (length $\times$ width; $\mathrm{n}=7$ ), and were approximately $6.85 \pm 0.72 \mu \mathrm{m}$ thick. The cytoplasm was colorless and transparent, and contained opaque particles (Fig.2A2).

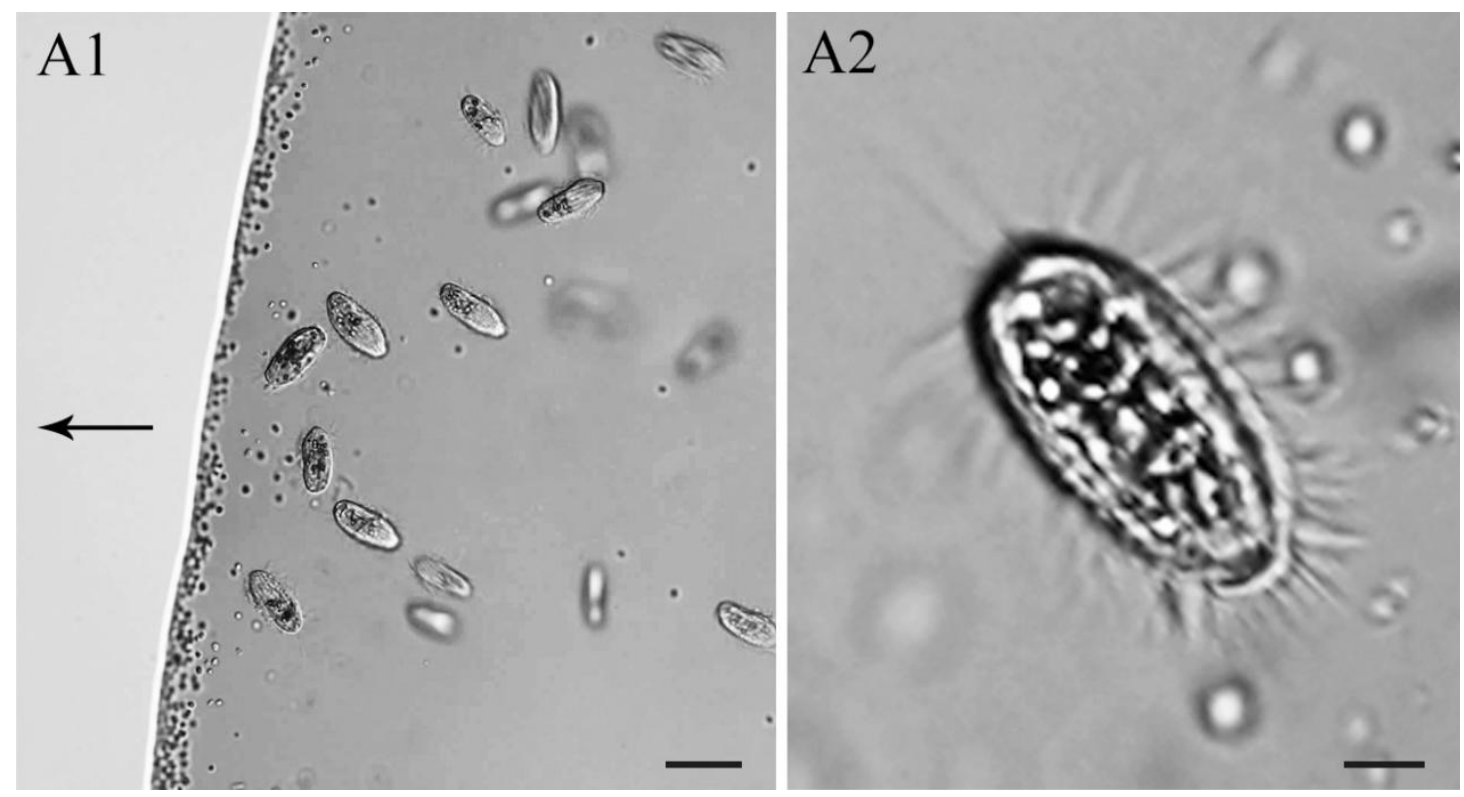

Fig.2 Light microscope images of magnetotactic bacteria and ciliates. A1: co-occurrence of magnetotactic bacteria (dark dots) and ciliates in a hanging drop preparation. The arrow indicates the direction of the magnetic field. A2: magnified image of a ciliate. Scale bars: $20 \mu \mathrm{m}$ (A1), $5 \mu \mathrm{m}$ (A2).

\subsection{Phylogenetic analysis of the ciliate}

The 18S rRNA gene was cloned from the magnetically purified ciliates. In total, 50 clones were randomly selected for sequencing, and 26 complete 18S rRNA gene sequences were obtained; these sequences shared at least $99.4 \%$ identity and belonged to the same OTU, which was 
designated clone HQ (GenBank accession number MW082832). Among all 18S rRNA gene sequences in GenBank, the clone HQ sequence showed maximum sequence identities $(99.1 \%$, 99.2\%, 99.1\% and 99.0\%) with Uronemella parafilificum (HM236337), Uronemita parabinucleata (KU199245), Uronemella filificum (EF486866) and Uronemella filificum (MH574793), respectively. However, only Uronemella parafilificum (HM236337) showed 100\% query coverage to the clone HQ. Phylogenetic analysis based on 18S rRNA gene sequence analysis showed that the ciliate in our study is affiliated to the family Uronematidae. Hence, it is likely that clone HQ belongs to the species Uronemella parafilificum.

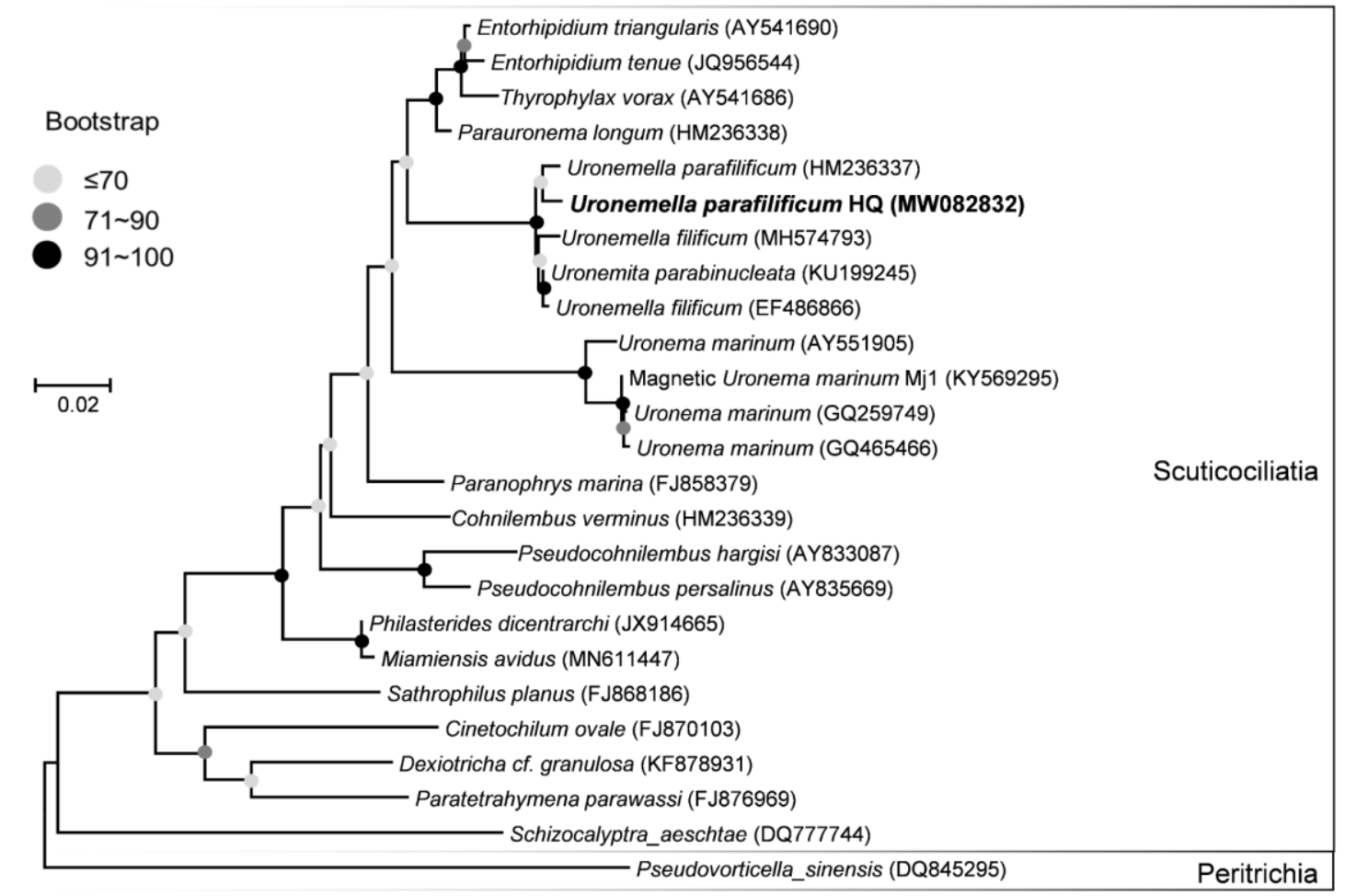

Fig.3 Maximum Likelihood tree for Uronemella parafilificum HQ based on $18 S$ rRNA gene sequences. The sequence determined in this study is shown in bold text. GenBank accession numbers of the sequences used are indicated in parentheses.

\subsection{Characteristics of magnetosomes in MTB and the ciliate Uronemella parafilificum HQ}

Generally, ciliate cells are too thick to be penetrated by the electron beam in transmission electron microscopy. However, ciliate cells are fragile and readily break up when dried on carbon-coated grids, and as a result magnetosome-like particles can be clearly observed. Two types of magnetosome-like particles were evident in the ciliate (Fig.4A), including: prismatic particles (rectangular elongated, elongated, and slightly elongated) having an average size of $93 \pm$ 
$25 \times 64 \pm 20 \mathrm{~nm}(\mathrm{n}=279, \mathrm{c}=9)($ Fig.5, A1-A3); and bullet-shaped particles having an average size of $115 \pm 9 \times 39 \pm 1 \mathrm{~nm}(\mathrm{n}=2, \mathrm{c}=1)$ (Fig.5, A4). In the lysed cells on the carbon films the magnetosomes were randomly distributed within the cell and were always arranged in chains.
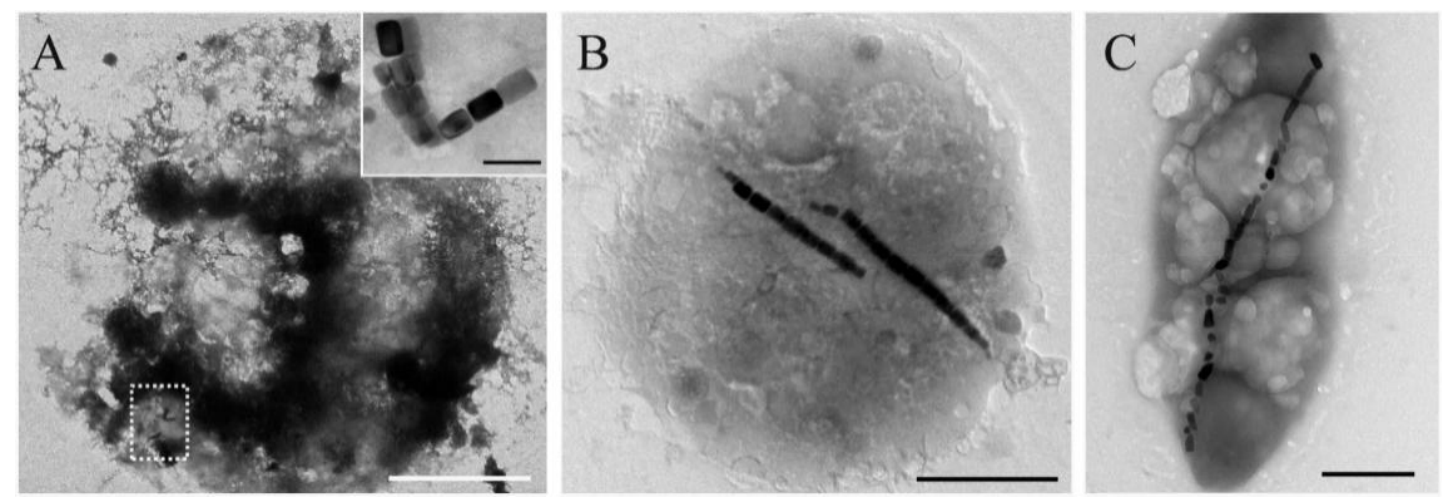

Fig.4 Transmission electron microscopy images of magnetotactic bacteria and ciliates. A: Uronemella parafilificum $\mathrm{HQ}$. The upper right insert shows an enlarged image of the area enclosed by the dashed line, in which variously shaped magnetosome-like particles are evident. B: magnetotactic coccus having elongated prismatic magnetosomes. C: rod-shape magnetotactic bacterium having bullet-shaped magnetosomes. Scale bars: $5 \mu \mathrm{m}$ and $200 \mathrm{~nm}$ (inset) (A); $1 \mu \mathrm{m}(\mathrm{B}) ; 500 \mathrm{~nm}(\mathrm{C})$.

Based on sample observation, magnetotactic cocci (Fig.4B) were dominant MTB in the samples, which also contained small numbers of rod-shaped (Fig.4C), curved rod, and spiral MTB. The cell morphologies and magnetosome shapes and arrangements were similar to those of marine MTB previously reported to have been isolated from the same sampling site in Qingdao (Xing et al., 2008). The average cell size of the magnetotactic cocci was $1.89 \pm 0.44 \mu \mathrm{m}(\mathrm{n}=70)$. The magnetosomes in the magnetotactic cocci were arranged in single or multiple chains, or occurred irregularly. The magnetosome shapes included elongated prismatic particles (rectangular elongated, elongated, slightly elongated) having an average size of $85 \pm 25 \times 58 \pm 20 \mathrm{~nm}(\mathrm{n}=718$, $\mathrm{c}=44)($ Fig.5, B1-B3), and cuboctahedral particles having an average size of $80 \pm 14 \times 76 \pm 11$ $\mathrm{nm}(\mathrm{n}=13, \mathrm{c}=1)$.

Among the other MTB morphologies (rod-shaped, curved rod, and spirillum) the magnetosomes were arranged in chains and had shapes including elongated prismatic (average size: $90 \pm 43 \times 56 \pm 23 \mathrm{~nm} ; \mathrm{n}=361, \mathrm{c}=21$ ), and bullet-shaped (average size: $105 \pm 29 \times 49 \pm 9$ $\mathrm{nm} ; \mathrm{n}=46, \mathrm{c}=3$ ) (Fig.5, B4). TEM observation revealed that elongated prismatic magnetosomes were often present, while the bullet-shaped forms were occasionally present. Energy dispersive $\mathrm{X}$-ray analysis indicated that the variously-shaped magnetosomes were composed of iron and 
oxygen (Fig.5; A5 and B5). Measurement of the crystal lattice and analysis of the electron diffraction pattern showed that the crystals were anisotropic magnetite (Fig.5; A6, A7, B6, and B7).
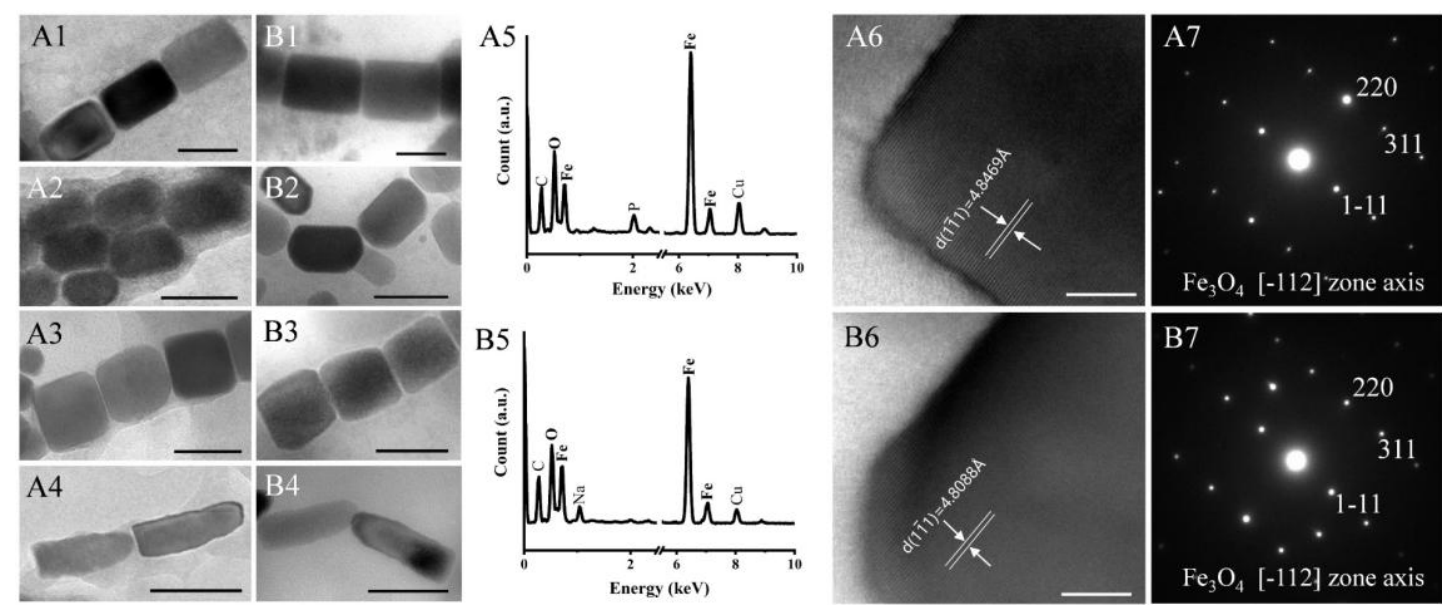

Fig.5 Characteristics of the magnetosomes in Uronemella parafilificum HQ and magnetotactic bacteria from

the same sample. Rectangular elongated prismatic magnetosomes from U. parafilificum HQ (A1) and magnetotactic cocci (B1). Elongated prismatic magnetosomes from $U$. parafilificum HQ (A2) and magnetotactic cocci (B2). Slightly elongated prismatic magnetosomes from $U$. parafilificum HQ (A3) and magnetotactic cocci (B3). Bullet-shaped magnetosomes from U. parafilificum HQ (A4) and rod-shaped MTB (B4). Energy dispersive X-ray spectra of rectangular elongated prismatic crystals from $U$. parafilificum HQ (A5) and magnetotactic cocci (B5). HRTEM images (A6 and B6) and electron diffraction patterns (A7 and B7) of the magnetosomes in A1 and B1. Scale bars: $100 \mathrm{~nm}(\mathrm{~A} 1-\mathrm{A} 4, \mathrm{~B} 1-\mathrm{B} 4) ; 10 \mathrm{~nm}(\mathrm{A6}, \mathrm{B} 6)$.

Statistical analyses were performed comparing the magnetosomes in MTB and $U$. parafilificum HQ with respect to length, width, shape factor, and size (Fig.6). The scatter plots generated show that the distributions of magnetosome length, width, and shape factor for $U$. parafilificum HQ were greater than that for the MTB, but the distributional trends was similar to that of the MTB (Fig.6: A1, B1, A2, B2). The frequency histograms for length, width, and size were also consistent between $U$. parafilificum HQ and MTB magnetosomes (Fig.6: A3-A5, B2-B5). 

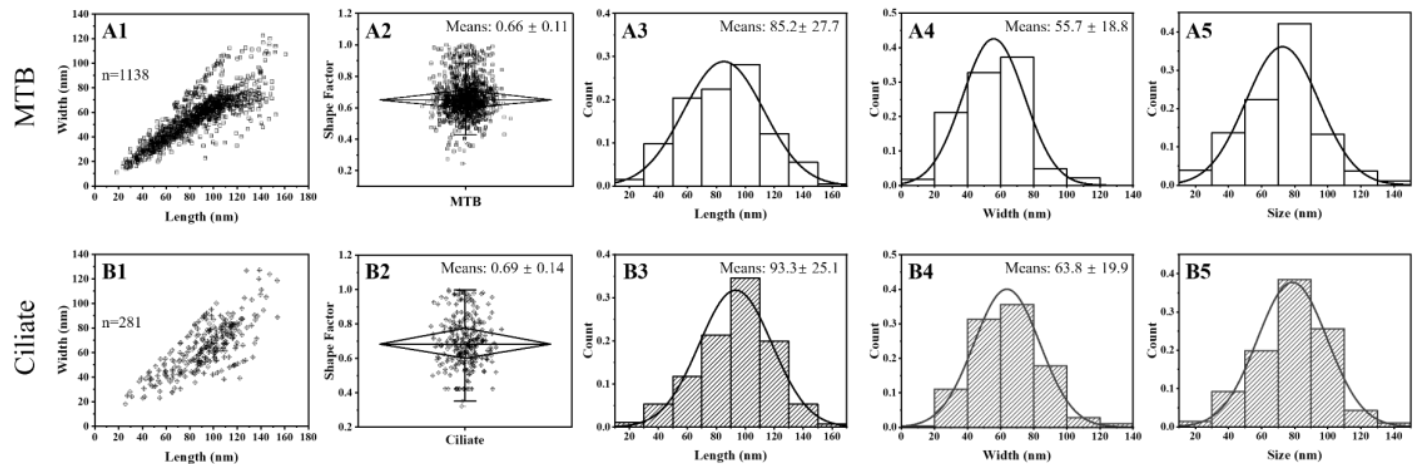

Fig.6 Comparison of the characteristics of magnetosomes in MTB and $\boldsymbol{U}$. parafilificum HQ. A1, B1: Dot plots of the length and width distributions of magnetosomes in MTB and U. parafilificum HQ. A2, B2: Dot plots of the shape factor distributions of magnetosomes in MTB and U. parafilificum HQ. A3, A4, A5: Frequency histograms of the length, width, and size ((length + width)/2) of magnetosomes, respectively, produced by MTB. B3, B4, B5: Frequency histograms of the length, width, and size ((length + width)/2), respectively, of magnetosomes in $U$. parafilificum $\mathrm{HQ}$.

\section{DISCUSSION}

The species $U$. parafilificum was first isolated from the top layer of sediment at a muddy site on the Ganghwa tidal flat and named by Gong et al. (2007). Morphological comparison showed that the species was present at two sampling sites. In the present study the ciliate $U$. parafilificum HQ was shown to contain magnetic particles having various shapes. A given magnetotactic organism typically synthesizes only one kind of magnetosome (Dieudonné et al., 2019; Mann et al., 1988). We found that the magnetosomes in U. parafilificum HQ and in the MTB from the same sampling site were very similar in shape, composition, and crystal size, suggesting that those in the ciliate were obtained by grazing on the MTB. Previous studies have shown that U.marinum $\mathrm{Mj}$ (which was collected from Calanque of Méjean, near Marseille is also affiliated to the family Uronematidae), can graze and ingest various types of MTB, and the predation of U. marinum $\mathrm{Mj} 1$ was thought to be non-selective (Monteil et al., 2018). In our study, characteristics of magmetosomes in $U$. parafilificum HQ were concordant with those in MTB. It seems that the predation of $U$. parafilificum $\mathrm{HQ}$ was not selective either.

Based on previous studies, MRPs share some common properties (Table 1): (1) they can be collected from natural environments using magnets; (2) they show similar magnetotactic behavior to MTB when observed by microscopy; (3) they contain magnetic particles; and (4) most magnetic 
ciliates can graze on MTB. In the present study the ciliate $U$. parafilificum HQ was obtained by magnetic collection from the sediment of an intertidal zone. It contained various shaped magnetic particles that were probably derived from grazing on MTB. However, typical magnetotaxis was difficult to observe in $U$. parafilificum $\mathrm{HQ}$. Although numbers varied, based on our observations no more than 200 magnetosomes were present in $U$. parafilificum HQ cells, and there was variability in the orientation of the magnetosome chains within the cells (Fig.4A). An average of 14272 magnetosomes acquired from grazed MTB were present in each cell of U. marinum Mj1, which showed obvious magnetotaxis and a rapid response to magnetic field inversion; the arrangement of most magnetosome chains was also apparently along the long axis of this ciliate (Monteil et al., 2018). Quantitatively, U. marinum Mj1 has > 700-fold the number of magnetosomes in $U$. parafilificum $\mathrm{HQ}$, even though their body sizes are almost the same. By contrast, in a feeding experiment the large ciliate Euplotes vannus $(78 \times 53 \mu \mathrm{m})$ did not respond to changes in the magnetic field about 30 min after it had ingested MMPs (Martins et al., 2007) it was estimated that there were thousands of magnetosomes from MMPs in each E. vannus cell. Thus, it may be that the magnetic response of ciliates when exposed to an applied magnetic field depends on the degree of accumulation of magnetosomes, and the arrangement of the magnetosome chains within each cell. The time taken for food particles to pass through a ciliate cell differs among species (Bernard and Rassoulzadegan, 1990; Dolan and Karel, 1997; Rassoulzadegan et al., 1988). We found dissolved magnetosomes in ciliate cells (Fig. S1), and that the proportion of small particles (length $<30 \mathrm{~nm}$ ) in ciliates $(1.07 \%)$ was lower than in MTB (1.49\%). This suggested that $U$. parafilificum HQ may have a digestion rate that is sufficiently fast to prevent a large number of magnetosomes from accumulating in its body. Video $\mathrm{S} 1$ shows that $U$. parafilificum HQ moved very rapidly in the hanging drop, and it may be that the rapid motion overwhelmed the weak magnetotaxis, making this phenomenon difficult to observe. Or, perhaps, its movement is fast enough for this type of ciliate to find sufficient food and a suitable habitat without help of magnetotaxis. Hence, the absence of a sufficient number of magnetosomes, fast digestion rate of the magnetosomes, and the disordered arrangement of magnetosome chains in $U$. parafilificum HQ may have resulted in it not showing any observable response to magnetic field changes. 
Table 1. Characteristics of various MRPs

\begin{tabular}{|c|c|c|c|c|c|}
\hline & Magnetic collection & $\begin{array}{c}\text { Typical magnetotactic } \\
\text { motion }\end{array}$ & $\begin{array}{l}\text { Magnetic particles } \\
\text { contained in cells }\end{array}$ & Prey on MTB & Reference \\
\hline Anisonema platysomum & $\sqrt{ }$ & $\sqrt{ }$ & $\sqrt{ }$ & & (Torres de Araujo et al., 1986) \\
\hline Flagellate & $\sqrt{ }$ & $\sqrt{ }$ & $\sqrt{ }$ & & (Monteil and Lefevre, 2020) \\
\hline Calkinsia aureus & $\sqrt{ }$ & $\sqrt{ }$ & & & (Monteil et al., 2019) \\
\hline Euplotes vannus & & & $\sqrt{ }$ & $\sqrt{ }$ & (Martins et al., 2007) \\
\hline Uronema marinum $\mathrm{Mj} 1$ & $\sqrt{ }$ & $\sqrt{ }$ & $\sqrt{ }$ & $\sqrt{ }$ & (Monteil et al., 2018) \\
\hline Dinoflagellate & $\sqrt{ }$ & $\sqrt{ }$ & $\sqrt{ }$ & & (Bazylinski et al., 2000) \\
\hline Cryptomonad & $\sqrt{ }$ & & $\sqrt{ }$ & & (Bazylinski et al., 2000) \\
\hline Cryptomonad & $\sqrt{ }$ & $\sqrt{ }$ & $\sqrt{ }$ & & (Bazylinski et al., 2000) \\
\hline Cyclidium sp. & $\sqrt{ }$ & & & & (Bazylinski et al., 2000) \\
\hline Uronemella parafilificum HQ & $\sqrt{ }$ & & $\sqrt{ }$ & $\sqrt{ }$ & \\
\hline
\end{tabular}




\section{CONCLUSION}

Based on morphological observations and 18S rRNA sequence analysis, we identified the species $U$. parafilificum $\mathrm{HQ}$ forming a population of benthic ciliates collected from intertidal sediments of Huiquan Bay (Qingdao, China). Uronemella parafilificum HQ was capable of grazing various types of MTB. Statistical analysis of the magnetosomes in U. parafilificum HQ cells and MTB from the same site suggested that the predation of $U$. parafilificum HQ appeared to be non-selective. The results add to knowledge of the broad diversity and wide distribution of MRPs, and provide opportunities for researching the mechanism of magnetoreception in eukaryotes.

\section{DATA TRANSFER STATEMENT}

The datasets generated and/or analyzed during the current study are available from the corresponding author on reasonable request.

\section{ACKNOWLEDGEMENT}

We thank Tang Xu, Liu Peiyu, and Liu Yan in the Electron Microscopy Laboratory, Institute of Geology and Geophysics, Chinese Academy of Sciences (EML, IGGCAS), for their efforts to maintain operation in TEM experiments.

\section{References}

Amor M, Mathon F P, Monteil C L, Busigny V, Lefevre C T. 2020. Iron-biomineralizing organelle in magnetotactic bacteria: function, synthesis and preservation in ancient rock samples. Environmental Microbiology, 22(9):3 611-3 632. https://doi.org/10.1111/1462-2920.15098.

Bazylinski D A, David R. Schlezinger, Brian H. Howes, et al. 2000. Occurrence and distribution of diverse populations of magnetic protists in a chemically stratified coastal salt pond. Biology Faculty Publications, 169(3-4):319-328. https://doi.org/10.1016/S0009-2541(00)00211-4.

Bernard C, Rassoulzadegan F. 1990. Bacteria or microflagellates as a major food source for marine ciliates: possible implications for the microzooplankton. Marine Ecology Progress Series, 64:147-155. https://doi.org/10.3354/meps064147. 
https://doi.org/10.1126/science.170679.

Dieudonné A, Pignol D, Prévéral S. 2019. Magnetosomes: biogenic iron nanoparticles produced by environmental bacteria. Applied microbiology and biotechnology, 103(9):3 637-3 649.

https://doi.org/10.1007/s00253-019-09728-9.

Dolan J R, Karel Š. 1997. Processing of ingested matter in Strombidium sulcatum, a marine ciliate (Oligotrichida). Limnology and Oceanography, 42(2):393-397. https://doi.org/10.4319/lo.1997.42.2.0393.

Frankel R B, Blakemore R P, Wolfe R S. 1979. Magnetite in freshwater magnetotactic bacteria. Science (New York, N.Y.), 203(4387):1 355-1 356. https://doi.org/10.1126/science.203.4387.1355.

Gong J, Choi J K, Roberts D M, Kim S Y, Min G S. 2007. Morphological descriptions of new and little-known benthic ciliates from Ganghwa tidal flat, Korea. The Journal of Eukaryotic Microbiology, 54(3):306-316. https://doi.org/10.1111/j.1550-7408.2007.00268.x.

Leão P, Le Nagard L, Yuan H, Cypriano J, Da Silva-Neto I, Bazylinski D A, Acosta-Avalos D, Barros H L de, Hitchcock A P, Lins U, Abreu F. 2020. Magnetosome magnetite biomineralization in a flagellated protist: evidence for an early evolutionary origin for magnetoreception in eukaryotes. Environmental Microbiology, 22(4):1 495-1 506. https://doi.org/10.1111/1462-2920.14711.

Lefèvre C T, Trubitsyn D, Abreu F, Kolinko S, Almeida L G P de, Vasconcelos A T R de, Lins U, Schüler D, Ginet N, Pignol D, Bazylinski D A. 2013. Monophyletic origin of magnetotaxis and the first magnetosomes. Environmental Microbiology, 15(8):2 267-2 274. https://doi.org/10.1111/1462-2920.12097.

Mann S, Nicholas H. C. Sparks, Michael M. Walker, Joseph L. Kirschvink. 1988. Ultrastructure, morphology and organization of biogenic magnetite from sockeye salmon, Oncorhynchus nerka: implications for magnetoreception. Journal of Experimental Biology, 140:35-49. PMID: 3204335.

Martins J L, Silveira T S, Abreu F, Silva K T, da Silva-Neto I D, Lins U. 2007. Grazing protozoa and magnetosome dissolution in magnetotactic bacteria. Environmental Microbiology, 9(11):2 775-2 781. https://doi.org/10.1111/j.1462-2920.2007.01389.x.

Medlin L, Elwood H J, Stickel S, Sogin M L. 1988. The characterization of enzymatically amplified eukaryotic 16S-like rRNA-coding regions. Gene, 71(2):491-499. https://doi.org/10.1016/0378-1119(88)90066-2.

Monteil C L, Lefevre C T. 2020. Magnetoreception in microorganisms. Trends in Microbiology, 28(4):266-275. https://doi.org/10.1016/j.tim.2019.10.012.

Monteil C L, Menguy N, Prévéral S, Warren A, Pignol D, Lefèvre C T. 2018. Accumulation and dissolution of magnetite crystals in a magnetically responsive ciliate. Applied and Environmental Microbiology, 
84(8):1-18. https://doi.org/10.1128/AEM.02865-17.

Monteil C L, Vallenet D, Menguy N, Benzerara K, Barbe V, Fouteau S, Cruaud C, Floriani M, Viollier E, Adryanczyk G, Leonhardt N, Faivre D, Pignol D, López-García P, Weld R J, Lefevre C T. 2019.

Ectosymbiotic bacteria at the origin of magnetoreception in a marine protist.Nature Microbiology, $\mathbf{4}(7): 1$ 088-1 095. https://doi.org/10.1038/s41564-019-0432-7.

Pan H, Dong Y, Teng Z, Li J, Zhang W, Xiao T, Wu L-F. 2019. A species of magnetotactic deltaproteobacterium was detected at the highest abundance during an algal bloom. FEMS Microbiology Letters, published Online on December 2019. https://doi.org/10.1093/femsle/fnz253.

Pan H, Zhu K, Song T, Kui Y- Z, Christopher L, Xing S, Liu M, Zhao S, Wu L. 2008. Characterization of a homogeneous taxonomic group of marine magnetotactic cocci within a low tide zone in the China Sea. Environmental Microbiology, 10(5):1 158-1 164. https://doi.org/10.1111/j.1462-2920.2007.01532.x.

Rassoulzadegan F, M. Laval-Peuto, R. W. Sheldon. 1988. Partitioning of the food ration of marine ciliates between pico- and nanoplankton. Hydrobiologia, 159(1):75-88. https://doi.org/10.1007/BF00007369.

Rodgers F, Blakemore R, Blakemore N, Frankel R, Bazylinski D, Maratea D, Rodgers C. 1990. Intercellular structure in a many-celled magnetotactic prokaryote. Archives of Microbiology, 154:18-22. https://doi.org/10.1007/BF00249172.

Schüler D. 2002. The biomineralization of magnetosomes in Magnetospirillum gryphiswaldense. International Microbiology, 5(4):209-214. https://doi.org/10.1007/s10123-002-0086-8.

Tamura K, Stecher G, Peterson D, Filipski A, Kumar S. 2013. MEGA6: Molecular Evolutionary Genetics Analysis version 6.0. Molecular Biology and Evolution, 30(12):2 725-2 729. https://doi.org/10.1093/molbev/mst197.

Torres de Araujo F F, M. A. Pires, R. B. Frankel, C. E. M. Bicudo. 1986. Magnetite and magnetotaxis in algae. Brief Communication, 50:375-378. https://doi.org/10.1016/S0006-3495(86)83471-3.

Wang R, Song W, Yi Z, Al-Rasheid K A S, Hu X. 2018. Morphology and molecular phylogeny of two new species of Spirostrombidium (Ciliophora, Oligotrichia), with a key to the species of Spirostrombidium. Systematics and Biodiversity, 16(8):743-756. https://doi.org/10.1080/14772000.2018.1484393.

Xing S, Pan H, Zhu K, Xiao T, Wu L. 2008. Diversity of marine magnetotactic bacteria in the Huiquan bay near Qingdao city. High Technology Letters, 18(3):312-317. https://doi.org/10.3772/j.issn.1002-0470.2008.03.017. (in Chinese with English abstract)

Zhang R, Chen Y, Du H, Zhang W, Pan H, Xiao T, Wu L. 2014. Characterization and phylogenetic identification of a species of spherical multicellular magnetotactic prokaryotes that produces both magnetite and greigite 
crystals. Research in Microbiology, 165(7):481-489. https://doi.org/10.1016/i.resmic.2014.07.012.

\section{Electronic supplementary material}

Supplementary material (Supplementary Video 1, Supplementary Fig.1) is available in the online version of this article at https:// 